\title{
A Review of Automotive Lightweight Technology
}

\author{
Hongwang Zhao ${ }^{\text {a }}$, Ruibin Zhang, Zeyun Bin \\ Guilin University of Aerospace Technology, Guilin 541004, China \\ azhw3721@qq.com
}

Keywords: lightweight technology, Structural optimization, Material, Technology.

\begin{abstract}
Reducing vehicle quality to reduce fuel consumption and reduce emission pollution is the core problem in the development of automobile industry. Lightweight design and improvement are urgently needed for new energy and traditional automobile. In this paper, the research status and development trend of vehicle lightweight technology at home and abroad is reviewed from three aspects, including structural optimization design, lightweight material application and advanced manufacturing technology.
\end{abstract}

\section{Introduction}

In recent years, with the rapid increase of car ownership, changing people's work and life, but a series of problems with the energy shortage and environmental pollution have become increasingly prominent, saving energy and reducing environmental pollution have become the two core problems of the automobile industry to be solved[1]. According to statistics, each weight loss of a car is $10 \%$, and the fuel consumption can be reduced by $6 \% \sim 8 \%$. Therefore, reducing auto weight is one of the most basic ways to save energy and improve fuel economy and reduce environmental pollution [2]. In addition, the light weight of the car is also beneficial to the improvement of the power, comfort and handling stability of the car. In this paper, the current research status of automotive lightweight technology at home and abroad is reviewed, and its future development direction is pointed out.

\section{Classification of Automobile Lightweight Technology}

The automotive lightweight technology can be divided into 3 main aspects, such as structural optimization design, the application of lightweight materials and advanced manufacturing technology [3], as shown in Fig.1.

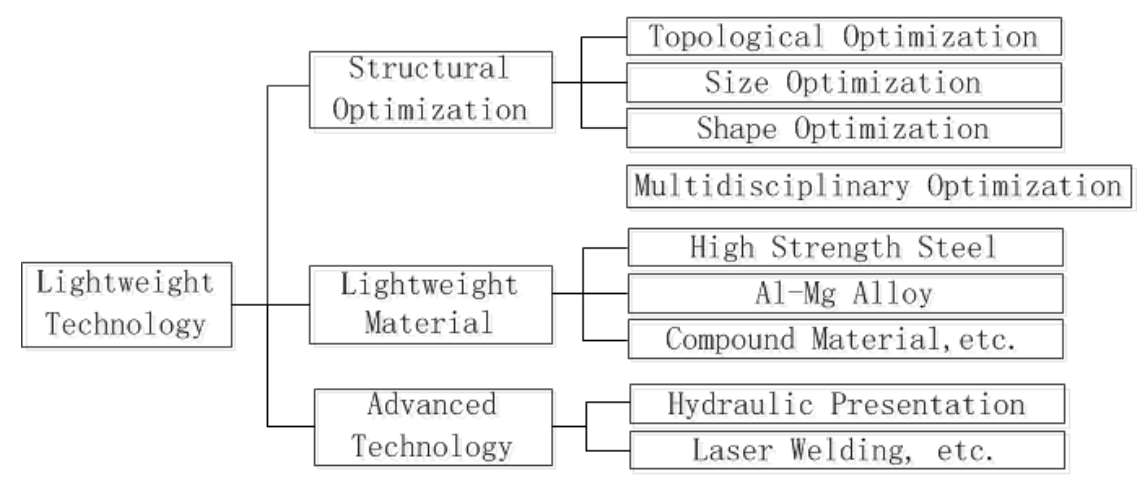

Fig.1 Classification of automobile lightweight technology

\section{Structural Optimization Design}

In modern automotive industry, the use of CAD/CAE/CAM integration technology plays a very important role, covering all aspects of automobile design and manufacturing. Using these technologies, the lightweight design and manufacture of automobile can be realized. One of the means of lightweight is to analyze and optimize the overall structure of the automobile, and to realize the simplification, integration and light quality of auto parts. There are 3 aspects in the rational design of concrete structure. Firstly, the structural optimization design can reduce the quality of the body frame 
and body steel plate, check the strength and stiffness of the car body, ensure that the car can reduce self-weight on the premise of satisfying the performance [4]. Sencondly, through the miniaturization of the structure, the light weight of the car is promoted, and the size of the car is reduced mainly by its main functional components under the same performance [5]. Thirdly, taking the change of sports structure to achieve the goal [6]. In recent years, the theory and method of lightweight and tool software are constantly emerging, and the automobile companies are more widely used in structural optimization design to realize automobile lightweight. The optimization design of automobile structure has gone through: size optimization, shape optimization, topology optimization, multidisciplinary design and optimization, and other stages.

\section{Application of Lightweight Materials}

The development and application of lightweight materials are another main research direction of current automotive lightweight technology. The research of lightweight materials is one of the most active research directions in the field of automotive materials at present. In the field of lightweight materials, the use of advanced high-strength steel and Al-Mg alloy instead of ordinary steel to make automobile main bearing components has become a trend. In addition, in order to meet the safety requirements of vehicle structure without additional quality, new energy absorbing materials, such as aluminum foam and braided composites, are applied to vehicle structures. According to statistics, the car body, the chassis (including suspension system), and the three large parts of the engine account for more than $65 \%$ of the total weight of a car, and the weight of the inner and outer cover of the body is at the top of the body. Thus reducing the weight of the car's body in white has a double effect on reducing the power consumption and reducing the total weight of the car. For this reason, we should find a breakthrough in the material making of the body in white. There are several options: Firstly, Light material with small density and high strength, such as aluminum magnesium alloy, plastic polymer material, ceramic material, etc [7].Sencondly, high strength steel with thin section thickness using the same density, the same modulus of elasticity and good process performance [8].Thirdly, Lightweight materials based on new material processing technology, such as continuous extrusion section, metal matrix composite plate, laser welded sheet, etc [9].

\section{Application of Advanced Manufacturing Technology}

With the application of high-strength steel, aluminum magnesium alloy, plastic and composite materials and lightweight materials and structures to achieve vehicle lightweight, the manufacturing process has also been applied. For example, the hot stamping process are used for high strength steel sheet stamping parts, adhesive bonding and adhesive welding technology are used for body structure connection. Hot stamping forms sheet metal forming in red hot state, while cooling quenching in the mold, stamping forming can strength up to $1.5 \mathrm{GPa}[10]$. Bonding process for the connection of plastic and composite parts[11].For example, BMW recently produced BMW I3 pure electric vehicle uses adhesive bonding process to connect the composite body parts, each vehicle uses a strong adhesive of about 10kg.On the other hand, some new forming and connecting processes, such as hydroforming and laser welding, can significantly reduce the quality of the car structure[12].For example, the car sub frame has been produced by stamping and welding process. It needs 6 stamping parts to be welded together, while the hydraulic forming technology only uses one part, and the quality is changed from $12 \mathrm{~kg}$ to $7.9 \mathrm{~kg}$, which reduces $34 \%$.Therefore, the advanced technology, such as hydraulic forming and laser welding, has been widely used, which has become an important part of the automotive lightweight technology.

\section{Summary}

In the aspect of structural optimization design, the size optimization, shape optimization and continuum topology optimization of automobile structure have been gradually developed and widely used. However, the multi-disciplinary and multi-objective optimization design method of the 
automobile structure and the topology optimization method of the discrete system structure still need further research and improvement.

In the application of lightweight materials, the deformation magnesium alloys, new plastics and fiber reinforced composites have great potential for application. In addition, it is difficult for a single material to satisfy the lightweight requirements of the automobile structure to the maximum extent. Researching on the design theory, method and process of mixed structure of various materials, different materials are used in different parts and the advantages of various materials are fully played, and the optimal combination of materials and parts can be realized, The theory and method of the multi material integration design will become the hot spot of automotive lightweight technology.

In terms of process research, hydroforming and laser welding will be more widely applied, and the application of hot forming technology and variable thickness plate will further develop.

In addition, the light weight of parts will be paid attention to. The research of automotive lightweight technology is the main body structure, and the total quality of the parts about the whole vehicle mass $3 / 4$, has great potential for lightweight. Therefore, the lightweight research on parts such as axle, suspension, gearbox, engine and so on will be paid more attention.

Moreover, various lightweight technologies are complementary to each other and give full play to the advantages of different means of light weight. The systematization and integration of automobile material selection, structure design and process design are also studied. It is also the development direction of Automotive Lightweight Technology in the future.

\section{Acknowledgments}

This work is carried out with the support of Guangxi junior high school teachers' basic ability improvement project (KY2016YB530); Scientific Research and Technology Development Program of Guilin (Grant No.2016010201).

\section{References}

[1]. Li J, Moul C C, Zhang W. Hoping grey goes green: air pollution's impact on consumer automobile choices [J]. Marketing Letters, 2017, 28:1-13.

[2]. Hao Han, Wang Sinan, Li Xiao,et al. A Research on CAFC Regulation-Oriented Lightweighting Strategy for Automotive Manufacturers [J].Automotive Engineering, 2017, 39(1):1-8.

[3]. Taub A I, Luo A A. Advanced lightweight materials and manufacturing processes for automotive applications [J]. Mrs Bulletin, 2015, 40(12):1045-1054.

[4]. Kitajima H, Kitajima H, Watson B C, et al. Structural optimization methods of nonlinear static analysis with contact and its application to design lightweight gear box of automatic transmission of vehicles [J]. Structural \& Multidisciplinary Optimization, 2016, 53(6):1383-1394.

[5]. Hai-Xia A N, Deng K, Zhi-Yue B I. Miniaturization and lightweight technology of high-power laser equipment [J]. Chinese Optics, 2017, 10(3):321-330.

[6]. Xiong F, Wang D, Ma Z, et al. Structure-material integrated multi-objective lightweight design of the front end structure of automobile body [J]. Structural \& Multidisciplinary Optimization, 2017(9):1-19.

[7]. Shi D, Wang L, Liu D, et al. Materials and Technology of Automobile Chassis Lightweight[J]. Hot Working Technology, 2016.

[8]. Hörhold R, Müller M, Merklein M, et al. Mechanical properties of an innovative shear-clinching technology for ultra-high-strength steel and aluminium in lightweight car body structures [J]. Welding in the World, 2016, 60(3):1-8. 
[9]. Farhana I E N, Majid M S A, Paulraj M P, et al. Determination of Volume Fraction of a Glass Fibre/ Matrix Composite Plate using Vibration Analysis[J]. Indian Journal of Science \& Technology, 2015, 8(20):974-6846.

[10]. Guo Y, Xu H, Li F, et al. Research on a combined hot stamping process of lightweight Steel/CFRP laminate components [J]. Forging \& Stamping Technology, 2016.

[11]. Pecce M, Ceroni F, Bibbò F A, et al. Steel - concrete bond behaviour of lightweight concrete with expanded polystyrene (EPS)[J]. Materials \& Structures, 2015, 48(1-2):139-152.

[12]. Seffer O, Pfeifer R, Springer A, et al. Investigations on Laser Beam Welding of Different Dissimilar Joints of Steel and Aluminum Alloys for Automotive Lightweight Construction [J]. Physics Procedia, 2016, 83:383-395. 